\title{
Arbor
}

\section{El CNI: al servicio de España y de los ciudadanos}

\author{
Rafael Jiménez Villalonga
}

Arbor CLXXX, 709 (Enero 2005), 153-181 pp.

El cambio de siglo ha supuesto, por un lado, la desaparición de algunas amenazas tradictonales para los Estados, centradas en las concepciones ideológicas, en la política de bloques y en la primacía de los intereses nacionales sobre los de las coaliciones $y$, por otro, la irrupción de otras que se han aprovechado, para emerger y consolidarse como tales riesgos, del aumento de la inestabilidad a escala mundial, de la utilización creciente de la violencia con fines políticos y de los avances tecnológicos, sobre todo en el campo de las telecomunicaciones y de la informática. Resulta indiscutible -y para nosotros como españoles, dolorosamente indiscutible - que la mayor de las amenazas es la representada por el terrorismo internacional.

En este nuevo marco, los servicios de inteligencia han tenido que modificar sus objetivos y sus estructuras, apoyándose en las opciones que les permitían las legislaciones de sus países. En España, la inexistencia de una normativa adecuada había incidido en la vida política de los últimos años del pasado siglo, haciéndose completamente imprescindible abordar un marco legal que permitiera afrontar con eficacia los nuevos retos del escenario nacional e internacional, así como que garantizara su actuación preservando los derechos de los ciudadanos y los de sus miembros.

Con esta idea, en mayo de 2002 vio la luz la actual legislación sobre el Centro Nacional de Inteligencia, que recogía el testigo del Centro Superior de Información de la Defensa (CESID) y que nacía con vocación de permanencia al obtenerse el respaldo de más del 95 por ciento de los diputados. En términos de prestigio, el legado del CESID era importante y habia dejado al Centro en un lugar muy destacado en la consideración internacional de sus homólogos. Mantener ese prestigio y, sobre todo, aumentar 
su eficacia es el reto al que se enfrenta el CNI con esta nueva legislación, que le proporciona los instrumentos necesarios para lograrlo.

Cómo es el CNI, cómo se definen sus objetivos y cuáles son sus medios y caracteristicas es lo que trata de exponerse en el presente texto.

\section{Introducción}

Describir el Centro Nacional de Inteligencia obliga a referirse a tres temas íntimamente relacionados con él, cuyo tratamiento facilitará una aproximación a su conocimiento, permitiendo identificarlo como uno más de los servicios de inteligencia que existen en los países desarrollados.

Y todo ello sin olvidar que por la propia esencia de los servicios (órganos de seguridad), los asuntos que tratan (los que afectan a los principios e intereses nacionales) y los procedimientos de trabajo (genuinos o, cuando menos, poco frecuentes en otros órdenes de la vida) es necesario mantener reserva sobre ellos y sus actividades. Lo que no quiere decir que no puedan revelarse muchos aspectos que ayuden a conocerlos, comprenderlos y, entendiéndolos como algo propio, también respetarlos. En todo caso, lo que se exponga con rigor y responsabilidad facilitará que se eliminen las suspicacias (cuando no temores) que, alguna vez, pueden haber generado en las sociedades de todos los países.

Los temas que nos van a permitir delimitar inicialmente el marco relativo al CNI son los siguientes:

¿Qué se entiende por inteligencia?

¿Cómo son los servicios de inteligencia en Occidente?

¿Cuáles fueron los antecedentes del CNI?

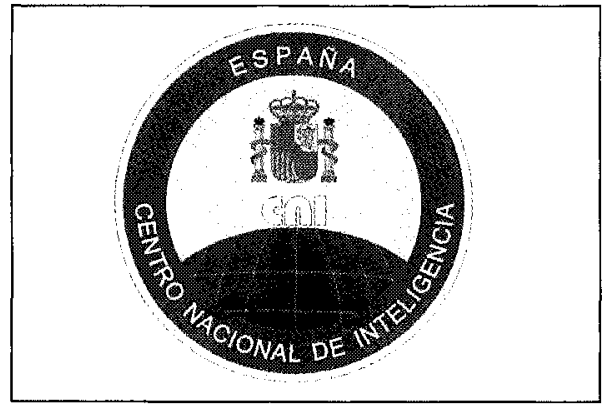

ESCUDO 


\section{El concepto de inteligencia}

Sin entrar en estudios profundos y eruditos sobre el concepto de inteligencia -lo cual quedaría al margen de este trabajo- es necesario precisar el término que identifica la tarea que se va a encomendar al CNI. Porque Centro ya da idea de que se trata de un organismo creado para alcanzar un fin determinado; y Nacional, que la dimensión de sus actuaciones responde al Estado en su conjunto. Por tanto, inmediatamente surge la necesidad de determinar la identidad de sus tareas, que lo diferencien de otros centros u organismos de ámbito o actuación nacional. En este sentido, el término Inteligencia se refiere al producto resultante de tratar convenientemente la información que interesa al Estado, es decir, la que precisan las autoridades responsables de proteger sus principios, fundamentos y patrimonio y promover sus intereses.

En síntesis, las informaciones que tengan alguna relación con dichos principios, fundamentos, patrimonio e intereses, si se someten a un proceso adecuado de tratamiento intelectual que permita enriquecerlas y utilizarlas oportunamente (en tiempo y sentido), adquieren un nuevo valor que se ha convenido en denominar inteligencia.

\section{Los Servicios de Inteligencia en Occidente}

No existe un modelo único y común de servicio de inteligencia en los países occidentales. Las ordenaciones legislativas, las tradiciones, las capacidades, las situaciones estratégicas, e incluso la historia de cada país, configuran un marco de situación que condiciona el número, la organización, misiones y actividades de sus servicios de inteligencia, así como su inserción en la estructura del Estado.

No obstante, sí pueden hallarse unos principios o elementos comunes en todos ellos, que permiten diferenciarlos de los servicios de los países con regímenes autocráticos.

La transparencia de las actuaciones de los poderes públicos es un principio fundamental de los Estados democráticos, lo que ha obligado a adecuar la necesaria reserva con la que deben actuar los servicios para asegurar su eficacia, con las garantías constitucionales de los ciudadanos. Reserva que no hay que entender como libertad para desarrollar cualquier tipo de actividad sin autorización y al margen de la ley, sino como discreción en el planeamiento y ejecución de sus tareas, que no de ben ser conocidas más que por aquellas personas encargadas de reali- 


\section{Rafael Jiménez Villalonga}

zarlas y las que, en los distintos niveles de decisión y ámbitos de poder, deban autorizarlas y controlarlas.

Derivado de este mismo principio puede considerarse el mismo hecho de la regulación legal de los servicios. Efectivamente, en los países autocráticos es frecuente la inexistencia de disposiciones que establezcan límites a la actuación de los servicios, o incluso que los reconozcan, convirtiéndolos en instrumentos del propio poder, que se vale de ellos para infundir el temor de lo oculto entre sus propios ciudadanos (hacia el interior) y para eludir el derecho internacional cuando posee alguna capacidad de actuación fuera de las fronteras (hacia el exterior), todo ello con la misma finalidad de la perpetuación de ese poder, impidiendo cualquier posibilidad de oposición al régimen establecido. Por el contrario, en los países democráticos no es concebible la inexistencia de un marco legal al que deba acogerse la actuación de sus servicios, que representa, en sí mismo, la garantía para dichos servicios y para la preservación de los principios constitucionales de los ciudadanos.

Un tercer matiz característico de los servicios de inteligencia en los países occidentales es la imposibilidad de actuar ante los riesgos o amenazas que conozcan, pues su misión debe limitarse a manifestar la existencia de dichos peligros para que los órganos competentes del Estado los

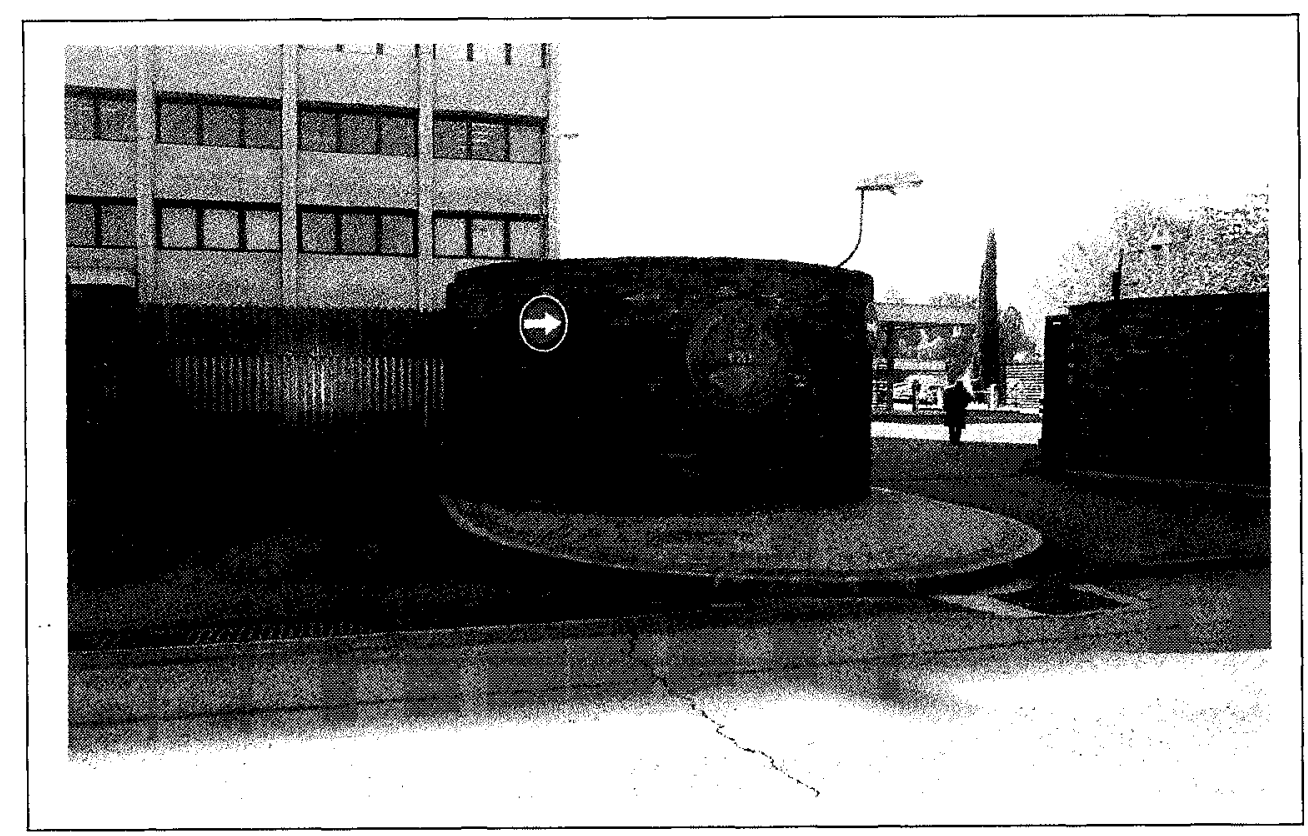

ENTRADA CALLE ARGENTONA 
neutralicen o reduzcan. Sin embargo, está ampliamente generalizada la actuación de los servicios de inteligencia en los países autocráticos para hacer frente a las amenazas que ellos mismos han detectado o, lo que es más grave y no menos común, que ellos mismos han creado. Esta actuación no justificada es la que ocasiona frecuentemente conflictos con los organismos departamentales encargados legalmente de oponerse a dichas amenazas, y también es causa de la desconfianza que generan en las sociedades por el grado de impunidad con que suelen aplicarse.

\section{Antecedentes del CNI}

La propia legislación sobre el Centro Nacional de Inteligencia establece que éste sucede al Centro Superior de Información de la Defensa, por lo que parece necesario hacer alguna referencia al CESID para conocer los rasgos generacionales del CNI.

\subsection{Origen del CESID}

El CESID se creó en 1977, en plena transformación de las estructuras del estado del régimen del general Franco a las de un estado democrático. Se aprovechó para ello la constitución del Ministerio de Defensa, en el que quedaban integrados los organismos de los tres Ministerios militares y los del Alto Estado Mayor. En la incorporación del CESID al Ministerio de Defensa aunque se mantuviera la dependencia del Presidente del Gobierno, debieron pesar razones de procedencia, de derecho comparado y de la propia naturaleza de sus funciones ante la inexistencia de un servicio que proporcionara la inteligencia estratégica de interés militar.

En cuanto a su procedencia, el CESID se organizó mediante la integración de funciones y cometidos del servicio de inteligencia que constituía la Tercera Sección del Alto Estado Mayor y del Servicio Central de Documentación (SECED). La primera de ellas desarrollaba las tareas correspondientes a un servicio de contrainteligencia y, de forma muy rudimentaria, las de un servicio de inteligencia exterior; mientras que el SECED aportaba responsabilidades en materia de servicio de inteligencia interior, siendo su finalidad el mantenimiento del orden institucional y la evolución ordenada al nuevo sistema democrático después de la muerte del general Franco. 
Aunque el SECED dependiera de la Presidencia del Gobierno, la conveniencia de separarlo del máximo representante del Ejecutivo -para protegerle de implicaciones no convenientes del Servicio- y el origen militar de la mayoría de sus miembros aconsejaron que su unión a la Tercera Sección del Alto Estado Mayor se produjera bajo la dependencia administrativa del ministro de Defensa.

En este mismo sentido se pronunciaba el derecho comparado, pues una vez decidida la existencia de un único servicio de inteligencia de nivel nacional, la dependencia de los servicios de inteligencia exterior de Francia, Italia, Portugal, Bélgica, etc., aconsejaba que, al igual que en dichos países, el nuevo servicio dependiera del ministro de Defensa.

Y también importante era la razón motivada por la naturaleza de sus funciones, entre las que prevalecían ante todas las que permitieran apoyar las decisiones en materia de política de defensa y de coordinación de la acción del Gobierno en la defensa del Estado, responsabilidad del presidente del Gobierno, pero cuyo componente principal, la política militar, correspondía desarrollarla al ministro de Defensa. Y éste no contaba entonces con un servicio de inteligencia que le proporcionara los elementos de juicio de carácter estratégico.

A todo ello hay que añadir, como se ha apuntado antes, que la mayor parte de los miembros del nuevo servicio eran o tenían procedencia militar y, sin un régimen de personal diferenciado, la forma más sencilla de gestionar los asuntos y aplicar un mismo y único régimen jurídico a su personal era mantenerlo bajo la administración y jurisdicción militar.

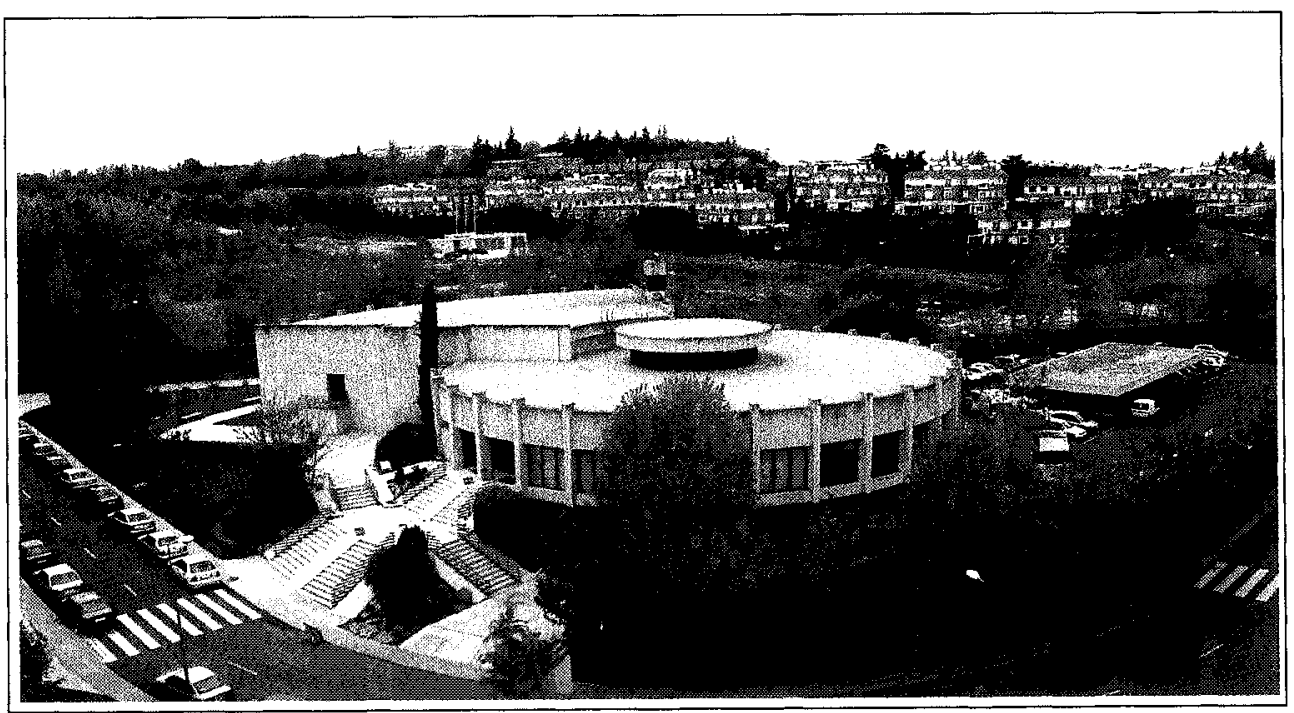

EDIFICIO SINGULAR 
El CNI: al servicio de España y de los ciudadanos

Con el paso de los años se pudo comprobar que la incorporación del Servicio al Ministerio de Defensa produjo algunos inconvenientes de orden social, siendo además utilizada varias veces con fines partidistas o políticos para erosionar al propio Ministro o para desprestigiar al $\mathrm{CE}$ SID. En ello hay que considerar también la propia denominación del Servicio, pues la expresión «de la Defensa» no se ha entendido casi nunca como algo que concierne a todos los españoles, sino como "de Defensa" y, por tanto, de la única responsabilidad del ministro del ramo, que debe llevar a cabo con sus únicos medios, los militares.

\subsection{Evolución del CESID}

Durante más de una década se mantuvo una regulación parcial del CESID, materializada mediante reales decretos y órdenes ministeriales, es decir, en ningún caso basada en principios de ley que se hubieran debatido en el Parlamento. Esto no quiere decir que fuera una anomalía, pues la mayoría de los países de nuestro entorno (europeos, a los que paulatinamente nos íbamos aproximando en todos los sentidos) habían optado por regulaciones ambiguas o incompletas. Las razones eran bien sencillas: el mundo bipolar dejaba bien claro quién era y dónde estaba el enemigo para cada bloque, y las sociedades confiaban la defensa de sus bienes al Estado, a quien otorgaban la facultad de decidir cuanto hiciera falta para ello, sin exigirle a menudo ninguna explicación.

Puede decirse, entonces, que ambos protagonistas, sociedad y Estado, se hallaban cómodos: la primera mantenía su desarrollo natural hacia el estado del bienestar al margen de las amenazas, de las que se encargaba el segundo, a cambio de que éste no se viera obligado a dar cuenta de sus actividades y de los medios con los que tuviera que hacer frente a tales amenazas. Y ello podía fácilmente justificarse, desde el punto de vista del Estado, porque la ocultación de dichas actividades y medios pretendía impedir, más aún, que los conociera el enemigo visible, argumento suficiente y convincente. Y uno de los instrumentos más eficaces de los Estados para hacer frente a las amenazas del otro bloque eran sus servicios de inteligencia. Por tanto, mantener en condición de indefinición su organización, medios y actividades, permitía aumentar la fortaleza de los Estados.

Pero hacia finales de los ochenta se fueron produciendo una serie de hechos que modificaron totalmente el «orden» bipolar. La caída del muro de Berlín, el desmembramiento de la Unión Soviética, la disolución del Pacto de Varsovia y la primera guerra del Golfo despertaron en Occidente las 
conciencias de sus sociedades, que ahora se preguntaban dónde estaba el tradicional enemigo que había justificado hasta entonces la existencia de importantes organismos de defensa, tanto puramente militares como de información. Se inició así la época de la determinación de los nuevos riesgos y la definición de las nuevas amenazas por los organismos de seguridad, al tiempo que los partidos políticos de la oposición se ocupaban de llevar la inquietud social a los parlamentos, exigiendo transparencia en la gestión y concreción de los medios empleados en la seguridad de los respectivos países. De este modo se puso en marcha un importante proceso de perfeccionamiento de las leyes sobre los servicios de inteligencia, que en algunos países suponía, de hecho, el afloramiento por primera vez en su historia legislativa de la misma existencia de dichos servicios.

En España, este proceso se vio más acusado por el propio desgaste del Gobierno del Partido Socialista, tras cuatro legislaturas consecutivas, creándose suspicacias en la sociedad sobre las actividades (reales o imaginarias) desarrolladas por el CESID, y utilizándose políticamente la inexistencia de normativa de rango legal que las amparase para erosionar al Gobierno.

$\mathrm{Al}$ iniciarse el año 1995, tres disposiciones regulaban el CESID, pero ninguna de ellas tenía rango legal. Tampoco se había abordado el régimen de su personal, cuya situación debía derivarse de una ley de 1989, constituyendo un motivo más en manos de la oposición para demostrar la falta de interés del Ejecutivo por encauzar el tema legal del Servicio.

A mediados de dicho año, 1995, se produjo la crisis del CESID por la sustracción y publicación de documentos del Centro, que dio lugar a la dimisión sucesiva de su Director, del ministro de Defensa y del vicepresidente del Gobierno. Esta crisis repercutió internamente en el Centro, modificándose su estructura mediante un nuevo real decreto y viendo también la luz (en julio de 1995) el estatuto de su personal, siendo éste, por tanto, la primera disposición desarrollada reglamentariamente a partir de una norma con rango de ley formal.

\section{Proceso legislativo y marco legal del CNI}

\subsection{Proceso legislativo}

Tras la celebración de elecciones generales en 1996, el nuevo Gobierno del Partido Popular se propuso abordar, de forma prioritaria, una legislación adecuada para el CESID, tal como había mantenido en su pro- 
grama electoral. La finalidad principal no sólo se justificaba por la necesidad de homologar la legislación sobre el Servicio con la de los países de nuestro entorno, sino, sobre todo, por la de evitar el uso partidista que de él podía realizar el Gobierno -según la Oposición- mediante el establecimiento de los correspondientes controles judiciales y parlamentarios.

A la vista de lo ocurrido y publicado hasta entonces, era absolutamente necesario establecer una legislación adecuada que garantizara derechos constitucionales de los ciudadanos $\mathrm{y}$, también, que amparara al Centro, y en particular a sus miembros, en el cumplimiento de algunas de sus misiones, durante cuya ejecución habían quedado desprotegidos.

Con este fin, en 1997 el Gobierno diseñó una regulación legal que partía de una nueva ley de secretos oficiales -la vigente era de 1967, reformada en 1978, aunque antes de promulgarse la Constitución-, de la que se derivaba la del Servicio de Inteligencia. Pero una filtración a medios de comunicación social sobre las sanciones que se impondrían a los medios que difundieran informaciones clasificadas provocó tan gran controversia que obligó al Gobierno a retirar los borradores de proyectos de ley, decidiendo no abordar nuevamente el problema hasta la siguiente legislatura.

En 2001, ya en la segunda legislatura del Gobierno del Partido Popular, éste recabó el consenso con otros grupos políticos representados en el Congreso, en particular con el PSOE, para elaborar las leyes que debían regular los servicios de inteligencia en España. Con ello se pretendía alcanzar el mayor acuerdo posible sobre la existencia, organización y funcionamiento de algunos de los organismos básicos destinados a proporcionar seguridad al Estado democrático, sustrayéndolos, en todo lo posible, a la acción de la alternancia política. La necesidad de proporcionar el mayor amparo legal a sus actuaciones, la estabilidad normativa necesaria para que su funcionamiento alcanzara el rendimiento que de ellos se espera y la conveniencia de evitar su utilización partidista en el futuro, merecían el esfuerzo de determinar la legislación que fuera aceptada por la mayor parte de las fuerzas políticas.

De esta forma, tras descartar la constitución de dos o más servicios (lo que hubiera supuesto dividir al CESID), sopesar las ventajas e inconvenientes de su dependencia de uno u otro ministerio y con el acuerdo mayoritario sobre las características de la persona destinada a dirigir inicialmente el Servicio, se llegó en 2002 a la actual regulación legal del Centro Nacional de Inteligencia, al que se le asignaba un nuevo nombre que, acertadamente, simplifica y determina con exactitud su verdadera esencia, al tiempo que elimina las connotaciones negativas que se habían manifestado en el del CESID. 
En la gestación de la normativa del CNI, en el tratamiento de sus principios básicos y en el ritmo aplicado a los trabajos técnicos y parlamentarios pesó decisivamente el acontecimiento que más influencia ha tenido en la percepción de la mayor amenaza actual, es decir, el terrorismo internacional, manifestado de forma trágica y sorpresiva el 11 de septiembre de 2001.

Por otra parte, también se hacía determinante salvaguardarle de uno de los principales riesgos que pueden afectar a un servicio de inteligencia: el de su politización. En este sentido, la legislación debía establecer cláusulas de garantía de continuidad institucional, de manera que, si bien su Director podría ser elegido únicamente por su capacidad política, el segundo cargo del Servicio debería responder a un perfil profesional en el ámbito de la inteligencia, y el resto de los miembros del Centro superar un proceso de selección adecuado al puesto de trabajo a ocupar.

\subsection{Marco legal}

El fruto de los acuerdos parlamentarios descritos anteriormente se materializó en la promulgación de dos leyes complementarias, una de las

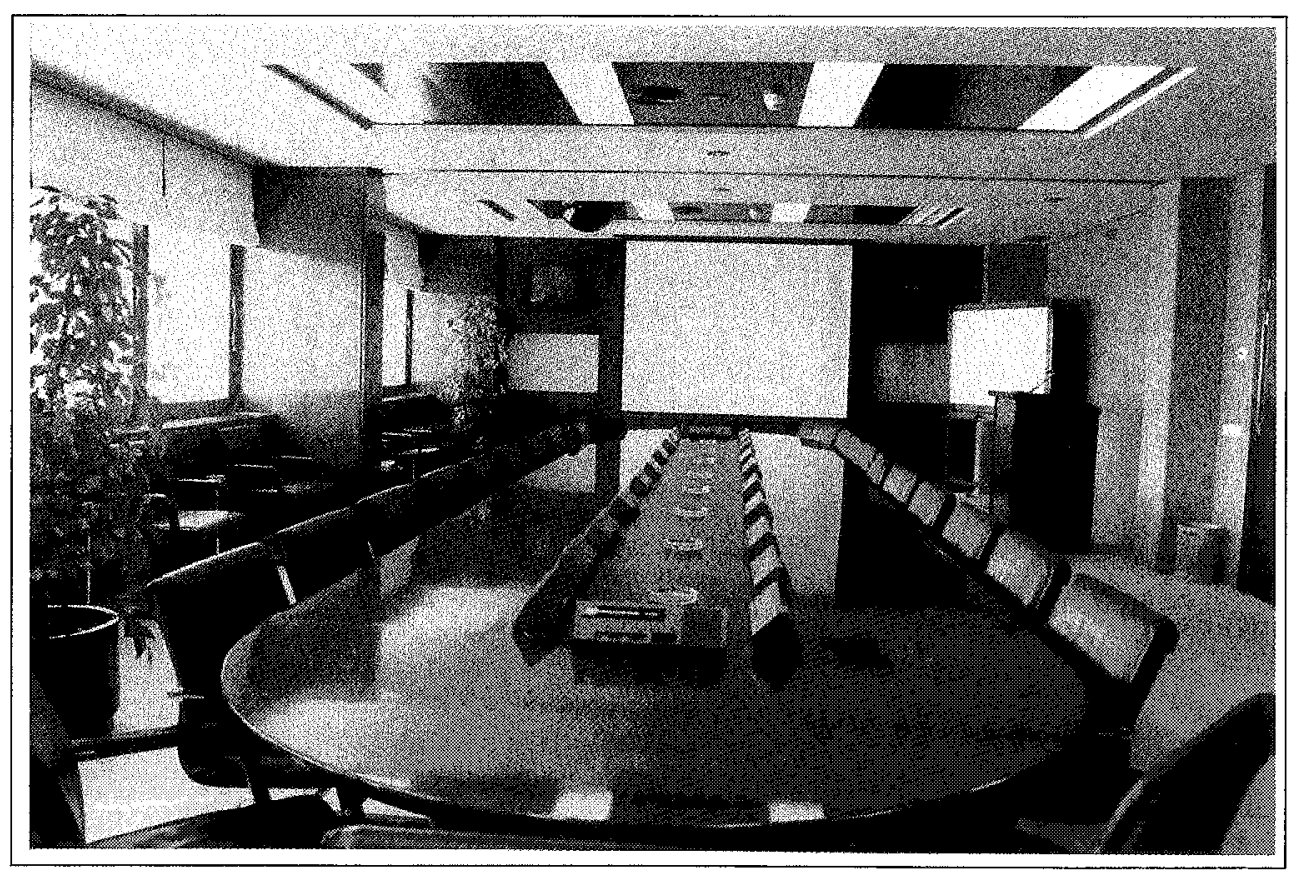

SALA REUNIONES PRINCIPAL 
cuales, ordinaria (L.11/2002, de 6 de mayo), regula el Centro Nacional de Inteligencia, mientras que la otra, de carácter orgánico (LO. 2/2002, de 6 de mayo), establece el control judicial previo al que deben someterse determinadas actuaciones del CNI. Ambas leyes deben interpretarse conjunta y sistemáticamente, pues la ejecución de las medidas extraordinarias que deban ser autorizadas previamente por el poder judicial tiene que justificarse en el cumplimiento de las funciones que se le asignan al Centro legalmente.

A las dos leyes anteriores les siguieron, también en 2002, dos reales de cretos, que desarrollan aspectos concretos de la ley del Centro: su estructura orgánica y su régimen económico presupuestario, respectivamente.

Más tarde y tras fracasar el intento de desarrollar simultáneamente otros dos aspectos de la Ley 11/2002, que otorgan al Secretario de Estado Director del CNI la condición de Autoridad Nacional de Inteligencia y Contrainteligencia y de director del Centro Criptológico Nacional, en marzo de 2004 se publicó el real decreto que regula este último Centro, al que adscribe al CNI y con el que comparte medios, procedimientos, normativa y recursos.

Completa el marco legal del CNI la disposición relativa al régimen estatutario de su personal, cuyo origen se produjo en 1995, como se ha expresado anteriormente (ver punto 4.2). Aunque la Ley 11/2002 contempla el desarrollo de un nuevo estatuto para el personal del CNI, razones de eficacia y seguridad jurídica han aconsejado la modificación del que ha permanecido vigente hasta la entrada en vigor de dicha Ley, haciéndolo en los términos necesarios para ajustarlo a las nuevas disposiciones, completarlo con los aspectos que la publicación urgente en 1995 había dejado incompletos, y corregir las disfunciones que su aplicación en los años de vigencia había puesto de manifiesto. Este real decreto fue publicado en febrero de 2004.

\section{Características del CNI}

El primer rasgo que caracteriza al CNI y lo distingue de otros servicios departamentales y operativos es su dependencia del Presidente del Gobierno, en particular, y del Gobierno, en general. Aunque su adscripción orgánica se mantiene al Ministerio de Defensa, la ley otorga al Presidente del Gobierno la facultad de modificar dicha adscripción mediante un real decreto. Ello confirma su dependencia del jefe del poder Ejecutivo y desmiente la naturaleza militar del Servicio, cualidad que 
frecuentemente se ha utilizado para descalificar a su antecesor, el $\mathrm{CE}$ SID, y tratar de limitar o encasillar sus funciones.

De esa misma dependencia directa del Gobierno se deriva una segunda característica: la definición de sus objetivos, que anualmente se le asignan mediante la aprobación en Consejo de Ministros de la Directiva de Inteligencia. Este documento recoge las necesidades de información de todo el Gobierno para asegurar los principios fundamentales del Estado y los intereses nacionales. La propuesta la realiza la Comisión Delegada del Gobierno para Asuntos de Inteligencia, que preside el Vicepresidente del Gobierno que designe su Presidente y de la que forman parte los ministros de Asuntos Exteriores y de Cooperación, Defensa, Interior y Economía, el Secretario General de la Presidencia y los Secretarios de Estado de Seguridad y del CNI, actuando este último como secretario de la Comisión. Los anteriores constituyen sus miembros permanentes, pero a sus reuniones pueden ser convocados los titulares de otros órganos superiores y directivos de la Administración General del Estado, lo que deja la puerta abierta a la participación de representantes cualificados tanto de la Administración Central como de la Autonómica.

Dado el nivel en el que se definen los objetivos, es fácil deducir que éstos abarcarán amplios escenarios internacionales o incluirán aspectos trascendentales para la seguridad del Estado, de tal manera que podrían considerarse agrupados en tres conjuntos. En el primero pueden hallarse los que afectan a los intereses de España en y frente al exterior, median-

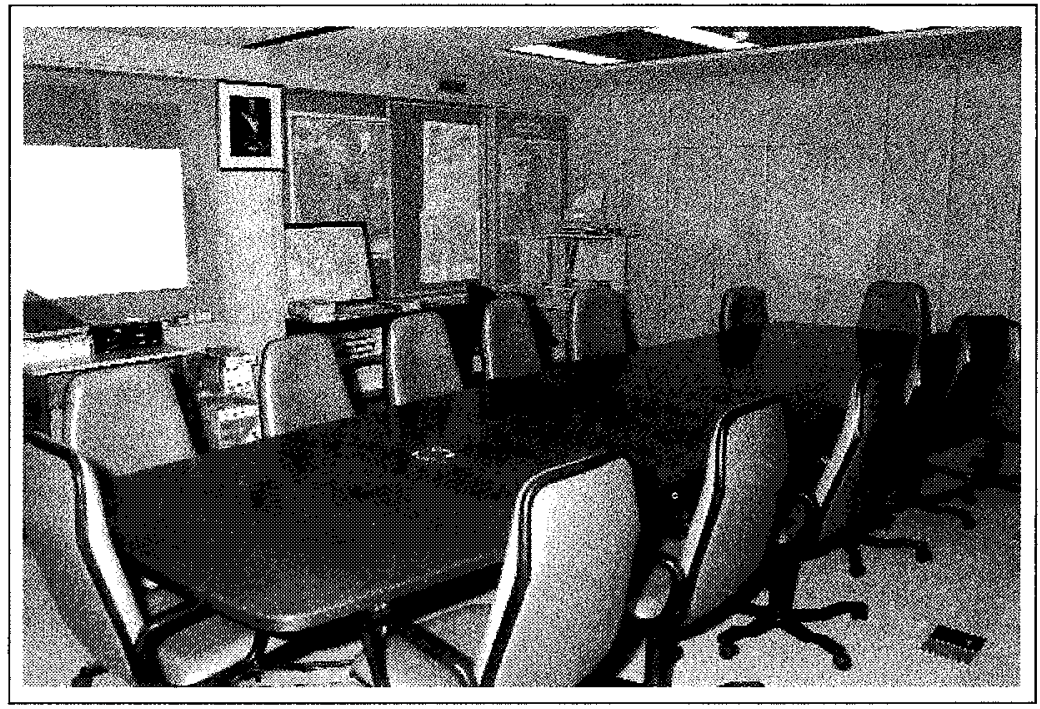

SALA DE REUNIONES 
te cuyo cumplimiento se asesora al Gobierno para que pueda fundamentar sus decisiones en la protección de dichos intereses y promoverlos como medio de aumentar la proyección nacional. La actividad que generan se conoce como inteligencia exterior. En un segundo conjunto pueden considerarse los que afectan a la seguridad de los bienes y los principios nacionales ante las posibles agresiones de grupos, personas o servicios de inteligencia de otros países, que darán lugar a la actividad conocida como contrainteligencia. $\mathrm{Y}$ en el tercer grupo se encuentran los que tienen por finalidad proteger la estabilidad institucional y proporcionar seguridad al país frente al terrorismo de cualquier naturaleza. De estos últimos objetivos se deriva la actividad denominada contraterrorismo.

La reciente legislación del Centro le ha introducido una nueva seña de identidad, al configurarlo como Organismo público especial, que le proporciona la necesaria autonomía funcional para el cumplimiento de sus misiones al dotarle de un régimen específico presupuestario, de contratación y de personal, que en la práctica se traduce en poseer personalidad jurídica y plena capacidad de obrar, pudiendo en su régimen patrimonial y de contratación someterse al derecho privado, así como actuar tanto dentro de España como en el exterior.

Esta misma autonomía le permite establecer su estructura orgánica con gran flexibilidad para adaptarse con rapidez a las necesidades informativas que impone la continua evolución de los acontecimientos.

También es característico del Centro su sistema de trabajo, que se inicia con la capacidad para adquirir la información que precisa mediante procedimientos específicos, no convencionales. En este sentido, la autonomía en la obtención de información constituye el factor más destacado para va lorar la eficacia de un servicio de inteligencia, cuyas fuentes, humanas o téc nicas, deben ser distintas de las utilizadas por la diplomacia, los medios de comunicación social y otras instituciones que se dedican a realizar estudios.

Los procedimientos de obtención a emplear con ambos tipos de fuentes requieren una preparación especial de las personas que deben llevarlos a la práctica, así como la utilización de una técnicas muy depuradas $\mathrm{y}$, en ocasiones, extraordinariamente complejas y costosas.

Una vez obtenida la información, la otra gran tarea que debe realizar un servicio de inteligencia es elaborarla, es decir, valorar, analizar, integrar e interpretar la obtenida de diversas fuentes, para convertirla en inteligencia y proceder a su difusión.

Otra característica del CNI es la que se deduce de los límites en sus funciones en cuanto a la producción de inteligencia y su futura utilización, de tal manera que, por un lado, está obligado a entregar toda la in- 
formación elaborada a las autoridades de las que depende; y, por otro, le está vedado tomar iniciativas, terminando su competencia precisamente en el momento en que proporciona el resultado de sus análisis.

Tal limitación se produce tanto en el ámbito exterior como en el interior: en el primer caso, el Servicio proporciona información sobre unas amenazas eventuales o sobre las posibilidades de desarrollo de los intereses nacionales, y señala sus características, pero es al Gobierno al que corresponde disponer, en su caso, las respuestas más eficaces para resolver los problemas que se le presenten o para utilizar de la mejor manera posible las capacidades de promoción de dichos intereses.

En el segundo caso, es preciso tener en cuenta que un servicio de inteligencia no es un organismo encargado de la aplicación de la ley; por consiguiente, su competencia no consiste en obtener evidencias de la comisión de un delito y poner a sus autores a disposición de los tribunales. $\mathrm{Su}$ misión consiste en detectar el riesgo o la amenaza y dejar que los órganos correspondientes establezcan la forma en que debe ser corregido o neutralizada, respectivamente.

Aunque no es exclusivo del CNI, sino de todos los servicios de inteligencia, es necesario aludir a la característica de secreto con que se clasifican determinadas materias relacionadas con ellos. El fundamento en el que la ley se basa para otorgar dicha clasificación se deriva de la necesidad de proteger la existencia misma del Estado, su seguridad y defensa frente a cualquier tipo de amenaza o agresión, siendo esta justificación no sólo doctrinal, sino que se sustenta constitucionalmente (CE, artículo 105) y en el derecho internacional (resoluciones del Convenio Europeo para la Protección de los Derechos Humanos y Libertades Fundamentales y del Pacto Internacional de los Derechos Civiles y Políticos).

En consonancia con lo anterior, la Ley 11/2002 califica con el grado de secreto las actividades, organización, estructura interna, medios, procedimientos, personal, instalaciones, bases y centros de datos, fuentes de información y las informaciones o datos que puedan conducir al conocimiento de las anteriores materias. Asimismo, impone la obligación de guardar secreto a los diputados que conozcan cualquiera de las anteriores materias en el ejercicio de su función de control parlamentario del Centro. Paralelamente, la Ley Orgánica 2/2002 también obliga al Magistrado encargado de efectuar el control judicial de las actividades del Centro a salvaguardar la reserva de sus actuaciones, que tendrán la misma clasificación de secreto.

Finalmente, es preciso hacer una referencia a la característica que le proporciona al CNI la adscripción del Centro Criptológico Nacional, máximo órgano de la Administración responsable de la seguridad de los sistemas de las tecnologías de la información que procesen, almacenen o transmitan información clasificada o información en formato electrónico, que normativamente requieran protección y que incluyan medios de cifra. 


\section{Misión y funciones}

La misión principal del Centro Nacional de Inteligencia es la de proporcionar al Gobierno la información e inteligencia necesarias para que pueda fundamentar sus decisiones en determinadas materias. Éstas se hallan definidas en el artículo 1 de la Ley reguladora del $\mathrm{CNI}^{1}$, del que se pueden extraer las siguientes conclusiones:

- La confirmación del Centro como único Servicio de Inteligencia de nivel nacional.

- La determinación como organismo público, formando parte de la estructura administrativa del Estado y, como toda ella, al servicio de los ciudadanos.

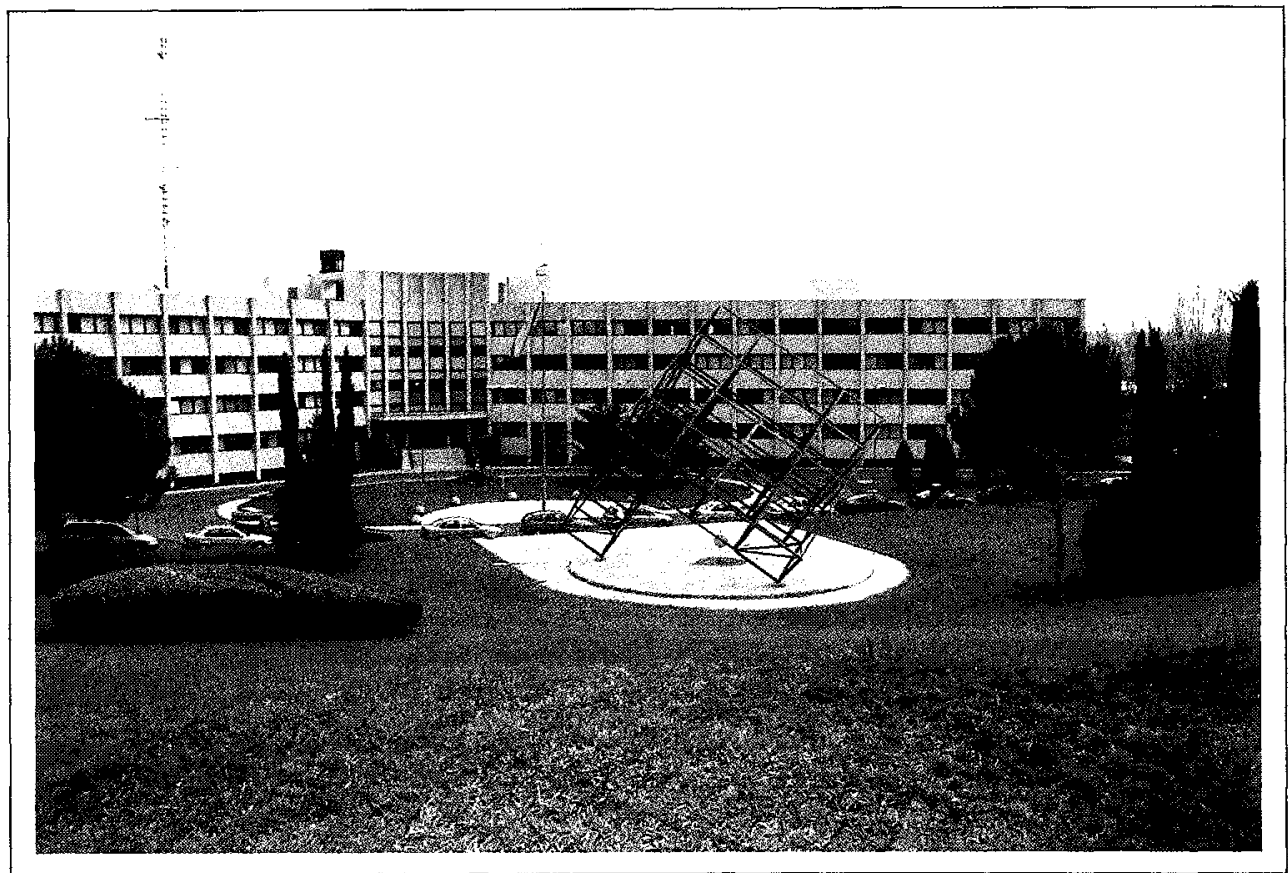

EDIFICIO ESTRELLA

1 «El Centro Nacional de Inteligencia es el organismo público responsable de facilitar al Presidente del Gobierno y al Gobierno de la Nación las informaciones, análisis, es tudios o propuestas que permitan prevenir y evitar cualquier peligro, amenaza o agresión contra la independencia o integridad territorial de España, los intereses nacionales y la estabilidad del Estado de derecho y sus instituciones». 
- La amplitud de destinatarios de su información, el Gobierno, destacándose al Presidente.

- La posibilidad de realizar propuestas, aspecto novedoso en la doctrina general sobre servicios de inteligencia, que le convierte en potencial orientador de la política del Estado cuando, a petición del Gobierno, haga uso de esta facultad.

- La responsabilidad de informar para prevenir, es decir, antes de que se haya manifestado cualquier peligro, amenaza o agresión.

- La amplitud de tareas que le asigna la Ley, que con la expresión intereses nacionales abarca la práctica totalidad de los ámbitos de una nación.

- La incapacidad para actuar ante las acciones de las que informe (ver punto 5).

En cuanto a sus funciones, es importante señalar que todas ellas contienen, explícita o implícitamente, el concepto de seguridad, en consonancia con lo que representa esencialmente un servicio de inteligencia, es decir, un organismo de seguridad del Estado. A continuación se realiza una breve descripción de cada una de las que señala el artículo 4 de la Ley 11/2002.

La primera ${ }^{2}$ es la que da lugar a la organización de la unidad de inteligencia que en otros países está atribuida al servicio de inteligencia exterior. De ella hay que destacar que se trata de la función que más genuinamente representa la labor de un servicio de inteligencia como organismo que debe obtener información, transformarla en inteligencia y difundirla a las autoridades del Estado que la precisen.

Del resto del contenido de esta función hay que destacar que la inteligencia que difunda el CNI debe también contemplar la promoción de los intereses nacionales en las áreas especificadas, así como la amplitud de campos de actuación que abarcan dichas áreas, teniendo en cuenta además que para lograrlo puede actuar dentro o fuera del territorio nacional.

La segunda función ${ }^{3}$ reúne la que debe asumir el Centro como servicio de seguridad interior, concentrando las tareas de contrainteligencia y

\footnotetext{
2 «Obtener, evaluar e interpretar información y difundir la inteligencia necesaria para proteger y promover los intereses políticos, económicos, industriales, comerciales y estratégicos de España, pudiendo actuar dentro o fuera del territorio nacional».

3 «Prevenir, detectar y posibilitar la neutralización de aquellas actividades de servicios extranjeros, grupos o personas que pongan en riesgo, amenacen o atenten contra el ordenamiento constitucional, los derechos y libertades de los ciudadanos españoles, la soberanía, integridad y seguridad del Estado, la estabilidad de sus instituciones, los intereses económicos nacionales y el bienestar de la población».
} 


\section{El CNI: al servicio de España y de los ciudadanos}

contraterrorismo, éste para hacer frente a la amenaza terrorista de cualquier naturaleza, actualmente, tanto la de origen islamista como la autóctona, que en España obliga a dedicar importantes recursos.

El hecho de que no se mencionen en esta definición las tareas propias del ciclo de inteligencia (obtener información, elaborar inteligencia y difundirla) no quiere decir que las unidades que se responsabilizan de esta función no las hagan, aunque sí es cierto que las realizan en menor medida, pues por su propia naturaleza estas acciones no precisan, en general, completar todo el ciclo.

De esta función hay que resaltar que el CNI debe posibilitar la neutralización de las amenazas, poniendo nuevamente de manifiesto la carencia de facultades para actuar ante ellas, ratificando asimismo la esencia de los servicios de inteligencia en España, cuyo límite de responsabilidad (ver punto 5) está en proporcionar la información que permita a otros organismos del Estado facultados para ello a actuar contra quienes pongan en riesgo, amenacen o atenten contra él.

También hay que destacar la amplitud de campos de actuación que abarcan las áreas que describe, entre las que figura el bienestar de la población, incorporada recientemente a la legislación de numerosos países occidentales como principio a lograr para sus sociedades.

El tercer cometido ${ }^{4}$ es en realidad un procedimiento para alcanzar un fin, el de hacer frente conjuntamente con los servicios de inteligencia de otros países a las amenazas globales de nuestro tiempo; pero, el hecho de que durante el proceso de gestación de la Ley se produjeran los atentados del 11 de septiembre de 2001, indujo seguramente a los legisladores a elevarlo al rango de función, convirtiéndola explícitamente en una de las tareas fundamentales para el Servicio.

La cuarta función ${ }^{5}$ reafirma el carácter único que se ha querido otorgar al CNI, al integrar en él las tareas que en otros países corresponden a otro servicio de nivel nacional independiente o enmarcadas en otros de naturaleza militar. El producto obtenido de la ejecución de esta tarea -conocida técnicamente como SIGIN'T, inteligencia de señales, e IMINT, inteligencia de imágenes- constituye un elemento de gran ayuda en los análisis que deben realizar las unidades de inteligencia.

\footnotetext{
4 «Promover las relaciones de cooperación y colaboración con servicios de inteligencia de otros países o de Organismos internacionales, para el mejor cumplimiento de sus objetivos».

5 «Obtener, evaluar e interpretar el tráfico de señales de carácter estratégico, para el cumplimiento de los objetivos de inteligencia señalados al Centro».
} 
La siguiente función ${ }^{6}$ es la que, fundamentalmente, da virtualidad al Centro Criptológico Nacional, organismo integrado en el CNI con responsa bilidades cada vez más importantes por el desarrollo de los medios técnicos. Como se ha visto anteriormente (ver punto 5) su desarrollo normativo se ha producido mediante un real decreto promulgado en marzo de 2004.

La pertenencia de España a distintas organizaciones internacionales le obliga a asumir y respetar las condiciones que dichas organizaciones imponen a sus miembros, en cuanto a la protección de la información clasificada que generan e intercambian. Con la sexta función ${ }^{7}$ se responsabiliza al CNI de exigir a los organismos que manejan dichas informaciones el exacto cumplimiento de las normas establecidas.

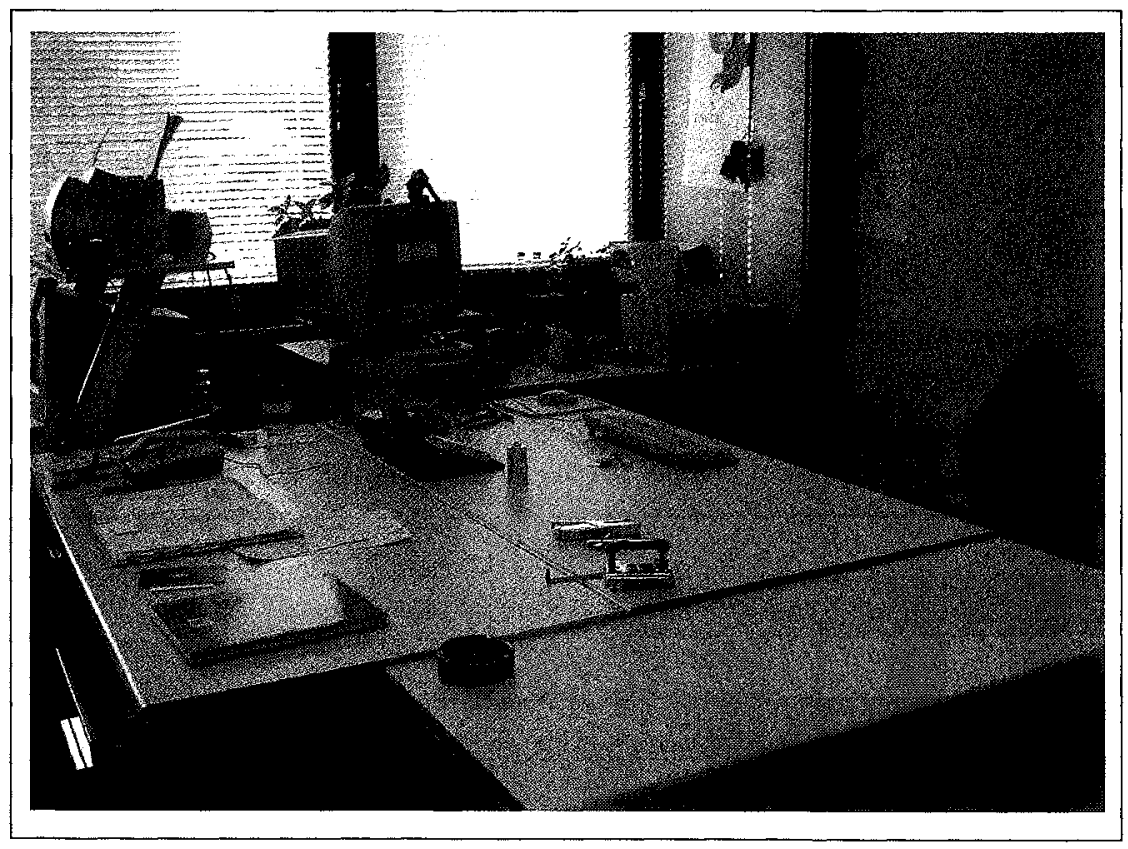

DESPACHO

\footnotetext{
${ }^{6}$ «Coordinar la acción de los diferentes organismos de la Administración que utilicen medios o procedimientos de cifra, garantizar la seguridad de las tecnologías de la información en ese ámbito, informar sobre la adquisición coordinada de material criptológico y formar al personal, propio o de otros servicios de la Administración, especialista en este campo para asegurar el adecuado cumplimiento de las misiones del Centrom.

7 "Velar por el cumplimiento de la normativa relativa a la protección de la información clasificada».
} 
El CNI: al servicio de España y de los ciudadanos

La última de las funciones ${ }^{8}$ que la Ley asigna al Centro le hace responsable de garantizarse su propia seguridad, sin tener que recurrir a las Fuerzas y Cuerpos de Seguridad del Estado, como ocurre con otros organismos de la Administración. Esta circunstancia implica la necesidad de conceder la consideración de agentes de la autoridad a los miembros del Centro que la desempeñen, que la poseen solamente durante el ejercicio de dicho cometido.

\section{Finalidad del CNI}

Como ya se ha expuesto, el CNI proporciona inteligencia al Gobierno para que pueda fundamentar sus decisiones relacionadas con dos aspectos: a) la protección y promoción de los intereses nacionales, y b) la seguridad de toda la sociedad. En esta doble finalidad radica la utilidad fundamental del Servicio y su contribución a la vida política, social y económica del Estado, entendido éste en su sentido más amplio.

La forma en que el Centro entrega el producto de su trabajo se traduce habitualmente en la remisión de notas informativas (análisis de acontecimientos concretos o en evolución), informes (temas concretos tratados monográficamente con la profundidad requerida), y boletines y síntesis informativas de carácter periódico (cuestiones de actualidad tratadas sistemáticamente).

Otra forma de materializar el cumplimiento de su misión principal -proporcionar inteligencia- la constituyen las numerosas reuniones de trabajo que mantiene con los servicios de información de las Fuerzas y Cuerpos de Seguridad del Estado, y con los órganos de la Administración civil y militar, tanto entre los órganos centrales del Centro con los de dichos servicios como entre los periféricos de ambos y con los autonómicos. El exponente más reciente del mantenimiento y desarrollo de la colaboración con los demás servicios del Estado lo constituye la incorporación, ya efectuada, de un equipo especializado del CNI al recién creado Centro Nacional de Coordinación Antiterrorista por el Ministerio del Interior.

Pero además de esta actividad fundamental de proporcionar inteligencia, el CNI puede llevar a cabo otras actividades que satisfacen o facilitan determinadas necesidades del Estado, utilizando procedimientos atípicos

\footnotetext{
8 «Garantizar la seguridad y protección de sus propias instalaciones, información y medios materiales y personales».
} 
cuando los convencionales no son aconsejables. Entre estas actividades destacan la realización de acciones de influencia y operaciones encubiertas, y el establecimiento de relaciones especiales y secretas con personas y organismos del interior y del exterior, que permitan abordar cuestiones delicadas que no pueden o deben tratarse por los cauces oficiales cuando éstos se han deteriorado o, esencialmente, no pueden asumir (negociaciones políticas, diplomacia secreta, liberación de rehenes, etcétera).

\section{El factor humano}

Como en todas las organizaciones que se precien, el factor humano constituye su principal patrimonio y, en el caso del CNI, esta aseveración está plenamente justificada como consecuencia del estricto proceso de selección y el completo sistema de formación de su personal. El esfuerzo y dedicación a estos aspectos son obligatorios, dadas las características del trabajo a desarrollar y la responsabilidad exigible a quienes lo desempeñen, pues de su eficacia y calidad pueden depender las mejores decisiones sobre la seguridad del Estado y los intereses nacionales.

\subsection{Selección de personal}

La naturaleza del Centro ha impuesto un régimen especial para satis facer sus necesidades de personal, eximiéndole de los sistemas habituales en la Administración, oferta pública de empleo y oposición. En consecuencia, el Centro ha constituido una base de datos abierta de fuentes de reclutamiento, en la que están registrados centros de formación profesional y de posgrado, colegios profesionales, escuelas de idiomas, etcétera. Con los candidatos que proporcionan estas fuentes y los que se obtienen por enviar su solicitud de ingreso a la página web del Centro (www.cni.es) se consigue una bolsa suficiente de la que iniciar la selección.

De acuerdo con la legislación vigente -Estatuto del Personal del CNI-, el ingreso de candidatos se lleva a cabo mediante un proceso de selección en el que se buscan las personas más idóneas para desempeñar los puestos de trabajo a ocupar. Éstos han sido definidos por sus características concretas (perfil) y agrupados por familias (Inteligencia, Técnicos, Traductores, Administrativos, Seguridad y Mantenimiento), de forma que permitan establecer procesos de selección específicos para cada una de ellas. No obstante, cada proceso se diseña en función del 
puesto a ocupar y, por tanto, el número y naturaleza de las fases que lo componen son variables.

De un modo general, las fases de cada proceso abarcan la superación de test psicotécnicos (para evaluar el potencial intelectual de la persona), evaluación de la personalidad (para descartar posibles psicopatologías), entrevistas personales con distintas finalidades, pruebas situacionales (ejercicios de simulación en los que se somete al candidato a una situación lo más cercana posible a su trabajo real), pruebas técnicas de conocimientos y pruebas de idiomas.

La selección parte de cinco requisitos ${ }^{9}$ que pueden ser exigidos en otros puestos de la Administración, de los que los específicos del puesto de trabajo constituyen la auténtica prueba de capacidad.

Para la familia de puestos de trabajo de Inteligencia, que son exclusivos del Centro, se ha diseñado un sistema de selección por competencias, que se basa en la observación y deducción de las características que definen a las personas con mucha experiencia que hayan demostrado un elevado rendimiento en su trabajo. De dichas características se ha obte nido el perfil de competencias, es decir, los rasgos que llevan al éxito en un entorno orgánico determinado, ya sean conocimientos, aptitudes, habilidades, motivaciones, personalidad..., todos ellos expresados en comportamientos concretos que pueden ser evaluados. Los candidatos deben superar cada una de las fases que constituyen el sistema de selección.

Para el resto de las familias de puestos de trabajo predominan las pruebas de capacidad técnica, sometiéndose a los candidatos a diferentes tareas que permitan valorar y establecer el orden de capacitación.

En cuanto a las características personales, el CNI no trata de seleccionar superdotados ni titulados con expedientes académicos brillantísimos, sino personas con un potencial intelectual normal, estables emocionalmente, activas y sociables, que cuenten con gran capacidad de trabajo, voluntad resistente, honestidad ideológica y personal, que posean o puedan alcanzar los conocimientos y habilidades necesarios para desempeñar ade cuadamente su puesto de trabajo, capaces de asumir responsabilidades, demostrar iniciativa, trabajar en equipo, tomar decisiones..., y, sobre todo, cuya motivación profesional no sea la económica o la promoción personal, sino que estén ilusionados por el tipo de trabajo y con ganas de prestar un servicio al Estado, es decir, con un acendrado espíritu vocacional.

\footnotetext{
${ }^{9}$ Nacionalidad española y mayoría de edad; titulación según el puesto de trabajo al que se opta; limpieza de expediente en el sector público y en los derechos ciudadanos; capacidad física y psíquica para el ejercicio de las funciones del puesto; y poseer o estar en condiciones de obtener la habilitación de seguridad acorde con el puesto de trabajo.
} 


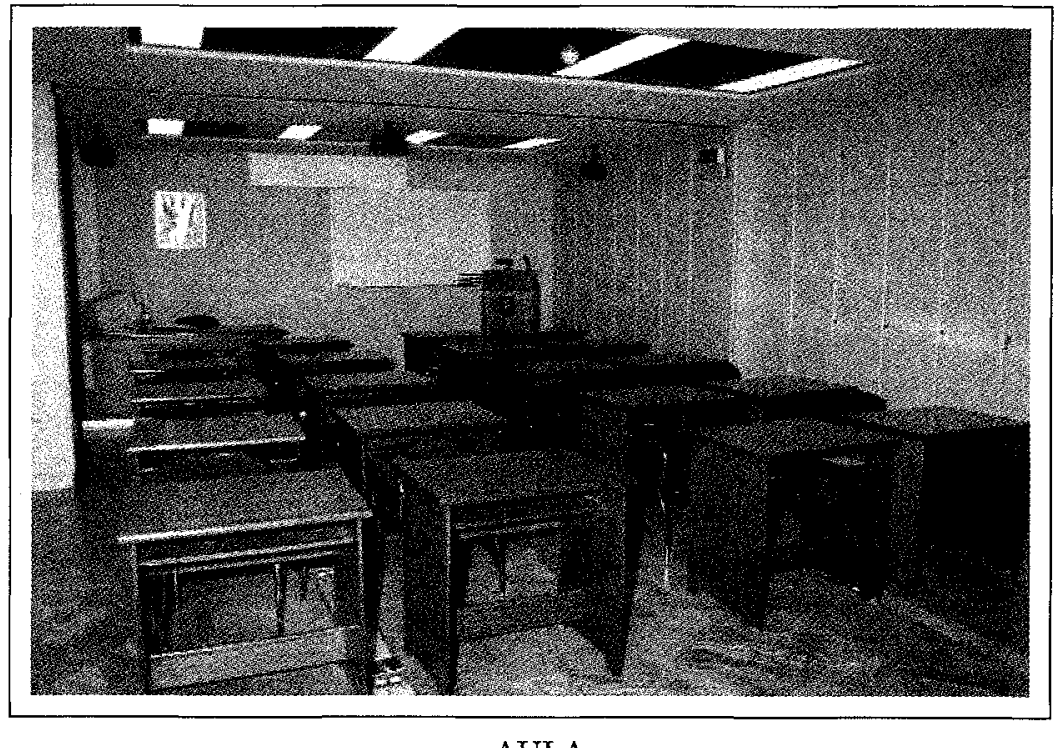

AULA

Simultáneamente a las pruebas descritas y de acuerdo con la Ley 11/2002, el Centro lleva a cabo investigaciones de seguridad sobre los candidatos, que permitan descartar reales o potenciales vulnerabilidades que, en caso de ingresar, pudieran poner en riesgo la seguridad del Centro o la de ellos mismos. Estas investigaciones deben completar el marco de seguridad exigible a cualquier miembro del Servicio, siendo la principal seña de identidad la de la discreción.

\subsection{Formación}

La formación en el CNI está concebida de forma integral, de manera que existe una enseñanza general, normalmente previa a la ocupación del puesto de trabajo y con finalidad, en algunos casos, también selectiva, una de especialización y una tercera de perfeccionamiento.

En cuanto a la enseñanza general, tiene como finalidad proporcionar los conocimientos necesarios para realizar funciones de inteligencia de acuerdo con el grupo de clasificación funcionarial, por lo que existen cuatro niveles pedagógicos. La superación del curso de inteligencia correspondiente es condición necesaria, aunque puede no ser suficiente, para ocupar un puesto de trabajo del grupo respectivo. 


\section{El CNI: al servicio de España y de los ciudadanos}

Para determinados puestos de trabajo, además de la formación general de inteligencia se exigen una o varias especialidades complementarias en técnicas concretas de inteligencia. Casi todos los cursos que integran esta enseñanza de especialización se imparten en el Centro.

Por su parte, la enseñanza de perfeccionamiento complementa las otras dos satisfaciendo las necesidades formativas del Centro en las distintas áreas de conocimientos: dirección, gestión, técnicas diversas, lingüística..., así como la actualización y ampliación de conocimientos en determinados ámbitos de interés para el Servicio, entre los que constituyen una parte muy importante los que se refieren al empleo y mantenimiento de los sistemas y medios tecnológicos más modernos de los que puede disponer el Centro.

Dentro de este tercer tipo de enseñanza hay que incluir también los seminarios de actualización y los ciclos de conferencias que se desarrollan habitualmente.

De esta manera se lleva a cabo una formación continua para la mayoría del personal del Centro, que suele hacerse imprescindible cuando se cambia de puesto de trabajo, y que responde al principio de que un miembro de un servicio de inteligencia no termina nunca de formarse, pues siempre se dispone de medios más modernos, las técnicas se depuran y las formas en que se presentan las amenazas varían, lo que obliga a mantener actualizadas y perfeccionar continuamente la preparación y formación de las personas encargadas de hacerles frente.

\subsection{Perfil del personal del Centro}

Con todo lo anterior, y por las condiciones de trabajo en un servicio de inteligencia, pueden deducirse unas características que identifican o afectan al personal del Centro. Es cierto que algunos de sus derechos superan los del régimen funcionarial común, siendo los más significativos los que garantizan la reserva en la gestión de su vida laboral y el de obtener la protección y el respaldo del Centro respecto a su actuación regular como miembro del mismo. También las posibilidades de promoción personal son atractivas, pues a las de la formación ya aludidas hay que añadir las de cambiar de actividad dentro del propio Centro, así como la de obtener un puesto de trabajo en el extranjero o en distintos lugares de España. Aun con todo, el verdadero atractivo lo constituye la propia naturaleza del trabajo, en el que es posible como en pocos otros observar la consecución de resultados en materias muchas de ellas de trascendencia nacional, enmarcada en una auténtica vocación de servicio a España. 
Pero al mismo tiempo, es evidente que los deberes también se ven incrementados respecto a colectivos similares. En primer lugar hay que aludir a la estricta neutralidad política y sindical, debiendo acomodar sus actuaciones al superior interés nacional. Este mismo principio impone la prohibición de sindicación y el del ejercicio de los derechos de huelga y de asociación con finalidad reivindicativa o política.

La necesaria discreción se convierte en deber de reserva permanente, también por mandato legal, obligándose a guardar secreto tanto sobre el Servicio como sobre los asuntos que trate.

Asimismo, se exige la dedicación absoluta y exclusiva al servicio y se impone, tras su baja en el Centro, el deber de abstención para desarrollar actividades relacionadas con los asuntos que haya conocido durante su permanencia en él.

La obligación del Servicio de hacer frente a cualquier peligro, amenaza o agresión impone a sus miembros su permanente disponibilidad, tanto en España como en el extranjero, cualidad que se practica en situaciones de normalidad diariamente y que se acusa de forma imperativa $y$ mucho más costosa en situaciones de crisis.

Desde un punto de vista intelectual, es necesario hacer referencia a que el trabajo del Centro exige una gran honestidad y rigurosidad para tratar las informaciones de las que son depositarios sus miembros, y una especial sensibilidad informativa para detectar los asuntos de interés para el Servicio.

Igualmente, se exige un claro sentido de la disciplina y el más ejemplar espíritu de servicio, al que deben ir unidos la lealtad, el mayor sentido del deber y un firme compañerismo. Estas virtudes, junto con la ya señalada exigencia de disponibilidad, han sido la mejor prueba puesta de manifiesto en los trágicos acontecimientos ocurridos en octubre y noviembre de 2003 en Iraq, que costaron la vida a ocho miembros del Centro.

\section{Los medios materiales}

La conveniencia de abordar este aspecto reside en el interés que suscitan los medios específicos de los servicios de inteligencia y su influencia para generar inteligencia de calidad, entendiendo por medios específicos los que realizan las funciones SIGINT e IMINT, a las que se ha hecho referencia anteriormente (ver punto 7).

Es sabido que las inteligencias de señales y de imágenes (genéricamente, inteligencia técnica) constituyen un elemento esencial en la obtención de información, e incluso en época reciente se ha llegado a valo- 
El CNI: al servicio de España y de los ciudadanos

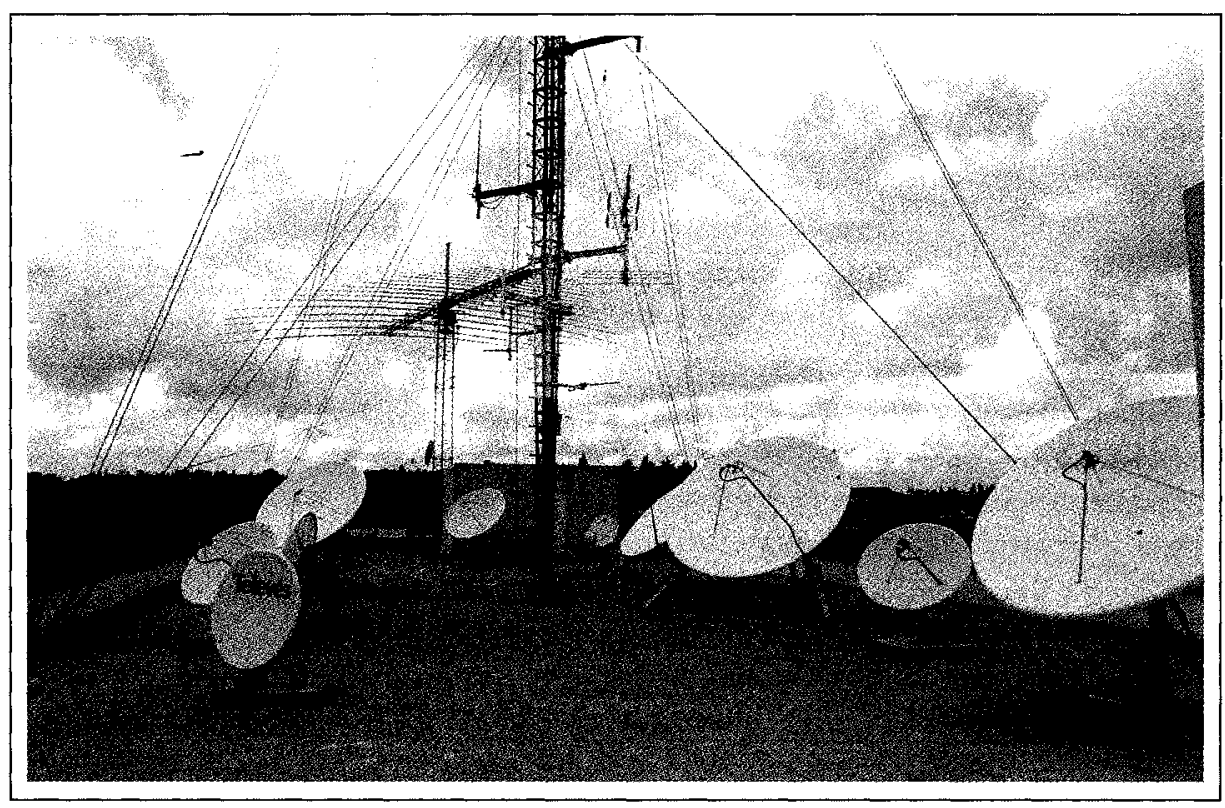

CAMPO DE ANTENAS

rar por encima de su importancia real, quizás porque representa un procedimiento que, por escapar al control efectivo de quien utiliza medios informáticos, comunicaciones, etcétera, o por el desconocimiento de sus verdaderas posibilidades, permite obtener informaciones muy valiosas. Pero en ningún caso puede considerarse un sistema sustitutivo de la inteligencia clásica o humana (HUMINT), es decir, de la que se obtiene a partir de las relaciones humanas y de las capacidades naturales del hombre y sus sentidos.

Consecuentemente, uno de los errores más importantes que puede cometer un servicio de inteligencia es el de querer excluir o minusvalorar la trascendencia de la adquisición HUMINT en favor de las otras citadas. El hecho que ha demostrado esta afirmación más palpablemente ha sido el sufrido por EE.UU. el 11 de septiembre de 2001. La capacidad de adquisición técnica (SIGINT e IMINT) de los servicios norteamericanos y de sus aliados se mostró insuficiente para evitar los atentados. ¿Quiere ello decir que si se hubiera invertido el mismo presupuesto en potenciar los medios de adquisición HUMINT se habría evitado el desastre? Evidentemente, no se puede asegurar, pero no cabe duda de que hubieran aumentado considerablemente las posibilidades de detección de la amenaza y, por tanto, de su prevención. 
¿Es conveniente, entonces, abandonar las inversiones en tecnología aplicable a la adquisición técnica para dedicarlas a la HUMINT? De ninguna manera, pues la evolución tecnológica y científica permite construir equipos de tratamiento y remisión de información cada vez más complejos y seguros, entendida esta seguridad en el doble sentido de garantía de fiabilidad y de protección de los productos que se almacenan y transmiten. Ante ello, los sistemas de captación de la información circulante deben desarrollarse simultáneamente para ser capaces de cumplir con su cometido, lo que impone mantener igualmente altas las capacidades de investigación y, por ende, de inversión.

¿En qué consiste la verdadera importancia de la inteligencia técnica? En ser el complemento idóneo de la humana y, a veces, la única posible. El primer aspecto lo cumple cuando sirve de alerta ante una situación de interés internacional: la época actual, definida tantas veces como la era de la comunicación, permite conocer un acontecimiento que se produzca en el mundo en muy poco tiempo y en cualquier lugar. Los servicios de inteligencia pueden utilizar sus capacidades de adquisición técnica para orientar los medios humanos a la obtención de información más precisa de tal acontecimiento.

Pero también la inteligencia técnica puede convertirse en esencial, cuando no es posible acceder al foco de la información, física o humanamente. En estos casos es preciso diversificar las fuentes técnicas para asegurar la bondad de la información obtenida, pues de otra manera no sería posible contrastarla. Ello exige, por tanto, grandes inversiones.

El gran problema se plantea entonces a la hora de decidir cuál debe ser el peso específico, personal y económico, a otorgar a cada tipo de adquisición. La solución, evidentemente, no puede ser matemática, pero debe estar en consonancia con la potencia del país y, sobre todo, con las amenazas más probables y peligrosas a las que deben hacer frente, en cada momento, sus servicios de seguridad. Actualmente, es fácil deducir que la mayor amenaza del mundo desarrollado es el terrorismo internacional, y está claro que éste no precisa medios sofisticados ni grandes inversiones para hacerse patente. Por tanto, no va a ser necesario, ni en general posible, dedicar costosas tecnologías para detectar a los posibles agresores. La principal herramienta de los servicios de inteligencia será, pues, el hombre. Lo que no debe excluir, no obstante, que deje de invertirse en tecnologías aplicadas a la inteligencia para atender a los otros objetivos de interés estratégico, que deben permitir al país mantener y mejorar su nivel de desarrollo y su lugar en el mundo; en definitiva, el bienestar de su población. 
El CNI: al servicio de España y de los ciudadanos

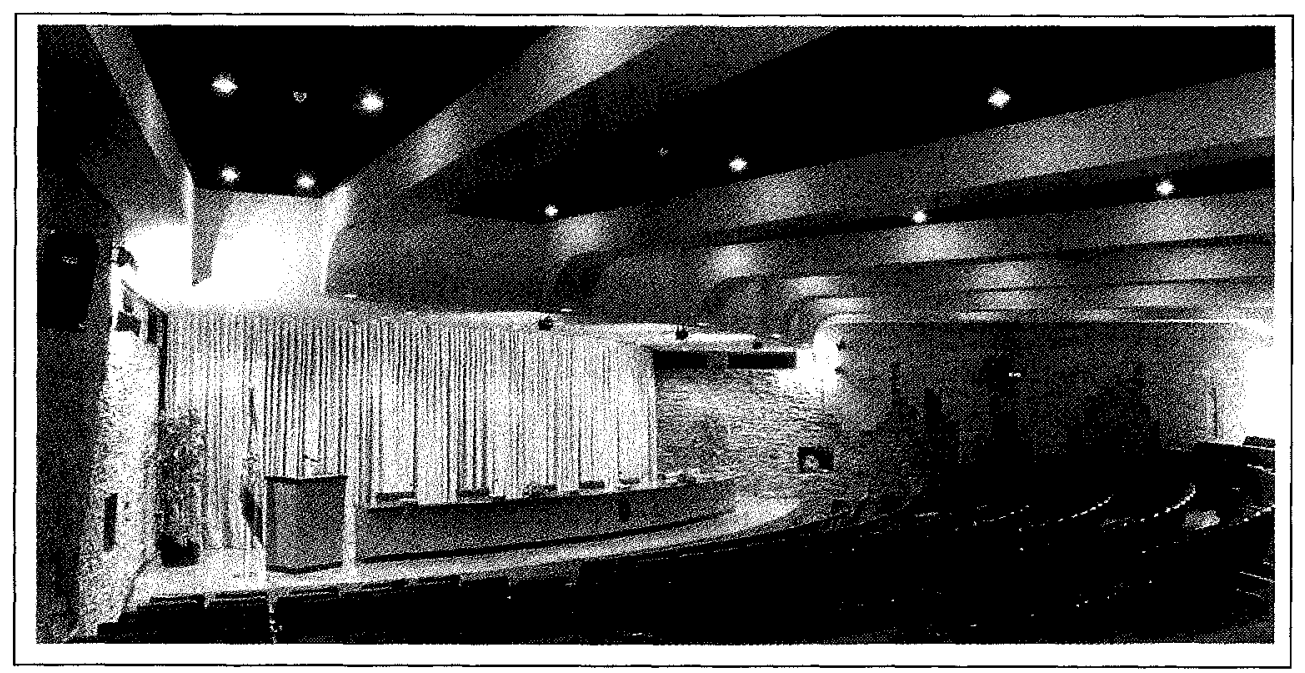

SALÓN DE ACTOS

\section{El control del CNI}

Uno de los argumentos más utilizados por el Partido Popular durante su oposición al Gobierno socialista a principios de los años 90 fue la falta de control del CESID, llegando a acusar al Ejecutivo de emplearlo en beneficio, no ya del Gobierno, sino del Partido Socialista, y, en cualquier caso, de realizar actividades al margen de la ley. Ciertamente, la inexistencia de regulación legal del Servicio abonaba estas acusaciones, algunas de las cuales se pusieron de manifiesto a raíz de la crisis que afectó al Centro en 1995 con la publicación de lo que se dio en denominar «los papeles del CESID», asunto ya juzgado. No obstante, también es cierto que la actividad general del Centro estuvo habitualmente controlada por los tres poderes del Estado, siendo buena muestra de ello las numerosas respuestas a diputados y senadores e intervenciones en sede parlamentaria del ministro de Defensa y del propio director del CESID, las solicitudes efectuadas al poder judicial para realizar actividades que podían vulnerar derechos constitucionales, a quien también se le remitían los resultados de las investigaciones llevadas a cabo, y el continuo control del presidente o vicepresidente del Gobierno y del correspondiente ministro de Defensa.

La legislación sobre el CNI y el procedimiento utilizado para llegar a ella-acuerdos entre la mayor parte de las fuerzas políticas- han venido 
a corregir el gran defecto de la ausencia de mecanismos completos de control. Como se ha expuesto anteriormente, las dos leyes promulgadas el 6 de mayo de 2002 contemplan de forma específica y por primera vez los controles parlamentario y judicial de las actividades del CNI.

En cuanto al primero de ellos, corresponde a la Comisión de control de los créditos destinados a gastos reservados conocer de los objetivos del Centro y del informe que anualmente elabore su Director sobre el grado de cumplimiento de aquéllos. Esta Comisión está compuesta por los mis mos diputados que conforman la de Secretos Oficiales, de acuerdo con el Reglamento del Congreso. La preside obligatoriamente el Presidente del Cámara y, actualmente, la componen ocho diputados más, uno por cada uno de los grupos parlamentarios, siendo la primera vez desde 1992, en que se aprobó la disposición sobre su composición, que forma parte de ella un representante del Grupo Mixto.

Asimismo, ante esta misma Comisión deben presentarse dos informes anuales sobre el consumo efectuado de los créditos destinados a gastos reservados, que, como una más de las partidas presupuestarias del Centro, aprueba anualmente el Parlamento.

A estos controles legislativos hay que añadir también el control económico-administrativo que efectúa el Tribunal de Cuentas, del que se informa al Parlamento.

Respecto al segundo, la Ley Orgánica 2/2002 está dedicada expresa y totalmente a determinar los mecanismos de control judicial a que deben someterse las actividades del Centro que afecten a los derechos constitucionales sobre inviolabilidad del domicilio y secreto de las comunicaciones. La Ley establece dos principios fundamentales: que la autorización para realizar tales actividades tiene que ser previa a su ejecución y que éstas deben ser necesarias para el cumplimiento de las funciones asignadas al Centro. El primer aspecto constituye una garantía para los ciudadanos superior a la establecida por legislaciones tan avanzadas como las de Francia o el Reino Unido, por ejemplo, democracias resueltamente consolidadas. Por su parte, la obligación de que el Magistrado del Tribunal Supremo competente para autorizar tales tipos de actividades al Centro compruebe que son necesarias para el cumplimiento de sus funciones implica, de hecho, la necesidad de que disponga de la Directiva de Inteligencia, completando con ello el marco de control judicial.

En cuanto al control del Ejecutivo, la nueva legislación sobre el CNI ha mejorado sustancialmente el que se ha venido llevando a cabo por todos los Gobiernos, ya que ha creado la Comisión Delegada del Gobierno para Asuntos de Inteligencia con misiones expresas de determinar los ob- 
El CNI: al servicio de España y de los ciudadanos

jetivos del Centro, que debe aprobar el presidente del Gobierno en Consejo de Ministros, y de realizar el seguimiento y evaluación del cumplimiento de dichos objetivos, lo que constituye la mejor garantía del control político permanente.

Además, esta Comisión tiene un tercer cometido: velar por la coordinación del CNI y de los servicios de información del Estado, lo que debería incluir en la práctica a los de los ministerios del Interior, Exteriores, Defensa y Hacienda, así como los de las Administraciones autonómicas que los posean. Este aspecto constituye una previsión de futuro, de difícil puesta en práctica actualmente y de auténtica decisión política, que sería altamente deseable en un mundo en el que gran parte del éxito de los servicios de información e inteligencia -cuya finalidad es lograr el mayor grado de seguridad posible para las sociedades-, reside en su coordinación y colaboración permanente. 